\title{
Comparison of Discounted and Undiscounted Cash Prices for Cardiovascular Medications by Type of US Community Pharmacy
}

\author{
Minji Hong, PharmD Candidate and Natalia Shcherbakova, PhD (i) \\ College of Pharmacy and Health Sciences, Western New England University, 1215 Wilbraham Rd., Springfield, MA, USA.
}

\begin{abstract}
BACKGROUND: Cash prices for prescription drugs vary among community pharmacies in the USA. GoodRx is a discount platform that provides coupons for use in community pharmacies without a membership requirement. Analytical pharmacy is a new type of pharmacy that tests drugs before dispensing to verify medication quality.

OBJECTIVE: To compare undiscounted and GoodRxdiscounted cash prices for common cardiovascular (CV) drugs by pharmacy type.
\end{abstract}

DESIGN: A cross-sectional study.

SETTING: GoodRx-discounted and GoodRxundiscounted cash price data; analytical pharmacy cash price data (all data collected in July 2020).

MEASUREMENTS: GoodRx cash price data for 30 units of 41 generic and 16 brand-name common cardiovascular medications at mass merchandiser, regional supermarket, two national chains, and analytical pharmacy (only one of its kind in the USA).

RESULTS: The average (SD) undiscounted generic CV medication cash price was $\$ 42.41$ (44.1). The average GoodRx-discounted generic CV medication cash prices were \$11.01 (8.6), \$9.88 (6.7), \$17.85 (10.5), and \$21.73 (14.1) in mass merchandiser, supermarket, and two national chain pharmacies, respectively. The average generic CV medication cash price was \$20.84 (25.7) at the analytical pharmacy. The average (SD) undiscounted brandname CV medication cash price was \$368.33 (127.00). The average GoodRx-discounted brand-name CV medication cash prices were \$269.16 (118.1), \$258.84 (108.6), $\$ 270.28$ (118.4), and \$274.60 (122.50) for mass merchandiser, supermarket, and two national chain pharmacies, respectively. The average (SD) brand-name CV medication cash price was $\$ 365.12(116.20)$ at the analytical pharmacy.

CONCLUSIONS: GoodRx-discounted cash prices of generic CV medications were significantly lower than undiscounted cash prices at supermarket, mass merchandiser, and national chain pharmacies. Analytical pharmacy cash prices too were significantly lower than traditional pharmacy undiscounted cash prices. GoodRx-discounted prices for brand-name CV medications did not differ significantly from undiscounted cash prices and between pharmacy types.

$\overline{\text { Prior presentations The findings from this study were presented in part }}$ at the Academy Health virtual national meeting in July-August 2020.

Received July 21, 2020

Accepted August 12, 2020

Published online September 3, 2020
KEY WORDS: drug prices; discount programs; community pharmacy; analytical pharmacy; cash prices.

J Gen Intern Med 36(1):114-20

DOI: $10.1007 / \mathrm{s} 11606-020-06149-7$

(c) Society of General Internal Medicine 2020

\section{INTRODUCTION}

Fifty percent of all Americans take prescription drugs for managing chronic diseases and nearly $70 \%$ of adults aged between 40-79 years use at least one at any given month. ${ }^{1,2}$ Medication non-adherence due to cost is common, especially among patients with a high cost-sharing plan or no insurance at all. ${ }^{3-6}$ These patients often pay out-of-pocket for prescription medications, with prices varying as much as several folds depending on the type of pharmacy. ${ }^{7,8}$ A patient may lower out-of-pocket cost by using a discount coupon offered by companies such as GoodRx and by choosing the pharmacy that offers the best price based on estimates from the company's website or mobile app. A patient without Internet access may obtain a paper coupon from a healthcare provider office but cannot take advantage of the price comparison function. Such a patient would benefit from the provider's ability to suggest a pharmacy type that is likely to offer a lower price. The most common types of pharmacies in the USA are national chain, mass merchandiser, supermarket, and independent pharmacies. ${ }^{9}$ These traditional pharmacies perform only visual inspections of medications they dispense. In response to recent concerns about drug quality, a new type of pharmacy called "analytical pharmacy" was launched. ${ }^{10,11}$ This pharmacy tests each lot of medications to verify that the concentrations of active ingredients, excipients, and impurities are within the FDAstipulated limits. The study's objectives were (1) to compare undiscounted and GoodRx-discounted cash prices of common cardiovascular (CV) drugs by pharmacy type and (2) to estimate each type's average gross margins for these drugs.

\section{METHODS}

\section{Data Sources and Study Drugs}

Of the 4.2 billion prescription medications dispensed in 2018 the USA, 1 in 5 are for an antihypertensive or a lipid regulator 
agent. ${ }^{12}$ Anticoagulants and other CV agents comprise an additional $3 \%$ of the overall prescription medication volume. ${ }^{12}$ The studied drugs included 41 generic and 16 brand-name CV medications. All of the generic CV agents belong to the list of top 200 most prescribed drugs and included antiarrhythmic, antihypertensive, antianginal, antiplatelet, antilipemic, and anticoagulant agents. ${ }^{13}$ Three of the 16 brand-name drugs too belong to the list of top 200 most prescribed agents.

\section{Exposures}

The independent variable in this study was the type of pharmacy. The following pharmacy types were included to compare their GoodRx-discounted cash prices with undiscounted cash price: national chain $(n=2)$, mass merchandiser $(n=1)$, regional supermarket $(n=1)$, and analytical pharmacy $(n=1)$. Analytical pharmacy does not accept GoodRx coupons and its undiscounted prices were compared with undiscounted cash price at traditional pharmacies.

\section{Outcomes}

For traditional pharmacies, we initially assessed cash prices at several cities in the state of Massachusetts, including Springfield, Worcester, and Boston. However, we identified limited ( \pm 10 -cent difference) to no variability in both undiscounted and GoodRx-discounted cash prices in the studied pharmacy types between cities. We also spot-checked cash prices in cities in several other states and found no cash price variability. As a result, we selected a single undiscounted and GoodRx-discounted cash price for each agent in each traditional pharmacy type based in the 01119 zip code of Springfield, MA. The analytical pharmacy's cash prices were assessed by creating a test account in the pharmacy's web portal. ${ }^{14}$ All cash prices were for 30 units of the medication in the most commonly prescribed strength. Data were collected in July 2020. Using the National Average Drug Acquisition Cost (NADAC) which is collected monthly by the Center for Medicare and Medicaid services from a nationally representative sample of community pharmacies, the average gross margin per brand and generic CV medication was also calculated for each pharmacy type during the same time period. ${ }^{15}$ NADAC is representative of an average amount a pharmacy paid to the wholesaler for acquiring a drug product.

\section{Statistical analyses}

As price did not vary within the same corporate pharmacy type across states and there is only one analytical pharmacy to study, we report overall undiscounted and GoodRxdiscounted mean cash prices across generic and brand-name $\mathrm{CV}$ medications by type of pharmacy. Analysis of variance with Bonferroni correction was used to compare undiscounted and GoodRx-discounted mean cash prices for each pharmacy type. Alpha level of 0.05 was adopted.

\section{RESULTS}

\section{Pharmacies}

Table 1 reports cash prices for three randomly selected CV agents from our sample from the three types of pharmacies in the vicinity of 01119 zip code that were collected via a telephone call in order to verify whether the cash price reported by the GoodRx website is comparable. There was no significant difference between the average cash price collected from the three pharmacy types via telephone and the average undiscounted cash price reported by the GoodRx website.

\section{GoodRx-Discounted Prices for Studied Generic and Brand-Name CV Drugs by Type of Pharmacy}

Tables 2 and 3 present data on GoodRx-discounted cash prices of studied agents at different pharmacy types together with average undiscounted (without GoodRx coupon) cash prices as reported on the GoodRx website and the National Average Drug Acquisition Costs. The average (SD) GoodRx-discounted generic CV medication cash price at mass merchandiser, supermarket, and two national chains (national chain\#1 and national chain \#2) were \$11.01 (8.6), \$9.88 (6.7), \$17.85 (10.5), \$21.73 (14.1), respectively (Table 2). The analytical pharmacy average (SD) generic CV drug cash price was $\$ 20.84$ (25.7) (Table 2). The price of generic CV agents at the mass merchandiser pharmacy was often fixed and did not require a GoodRx coupon. The average undiscounted cash price was significantly higher than GoodRx-discounted prices at each type of traditional pharmacies and the price at the analytical pharmacy ( $p<0.05$ for all five pair-wise comparisons). The average gross margins for generic $\mathrm{CV}$ medications were $\$ 5.84, \$ 4.71, \$ 12.68, \$ 16.56$, and $\$ 15.67$ for mass merchandiser, supermarket, national chains, and analytical pharmacy, respectively (Table 4). The average (SD) GoodRx-discounted cash prices for CV brand-name medications were \$269.16 (118.10), \$258.84 (108.60), \$270.28 (118.40), and $\$ 274.60$ (122.50) for mass merchandiser, supermarket, and national chain (national chain\#1 and national chain \#2) pharmacies, respectively (Table 3). The analytical pharmacy average (SD) brand-name CV drug cash price was \$365.12 (116.20) (Table 3). The average undiscounted brand-name drug cash price was not significantly different than average GoodRx-discounted cash price at different types of traditional pharmacies and the cash price at the analytical pharmacy ( $p>0.05$ for all comparisons). The average gross margins for brand-name $\mathrm{CV}$ medications were $\$ 22.43, \$ 12.10, \$ 23.55, \$ 27.86$, and $\$ 118.39$ for mass merchandiser, supermarket, national chains (national chain\#1 and national chain \#2), and analytical pharmacy, respectively (Table 4 ). 
Table 1 Comparison of Cash Prices by Type of Pharmacy Confirmed via Telephone with Average GoodRx website reported Cash Price ${ }^{1}$

\begin{tabular}{|c|c|c|c|c|c|c|}
\hline & $\begin{array}{l}\text { Mass } \\
\text { merchandiser }\end{array}$ & Supermarket & $\begin{array}{l}\text { National chain } \\
\# 1\end{array}$ & $\begin{array}{l}\text { National chain } \\
\# 2\end{array}$ & $\begin{array}{l}\begin{array}{l}\text { Average cash } \\
\text { price* }\end{array}\end{array}$ & $\begin{array}{l}\text { Average GoodRx reported } \\
\text { cash price }\end{array}$ \\
\hline $\begin{array}{l}\text { Amlodipine }(10 \mathrm{mg}) \\
\# 30\end{array}$ & $\$ 4.00$ & $\$ 12.99$ & $\$ 51.99$ & $\$ 57.99$ & $\$ 31.74$ & $\$ 29.49$ \\
\hline $\begin{array}{l}\text { Atenolol }(25 \mathrm{mg}) \\
\# 30\end{array}$ & $\$ 4.00$ & $\$ 6.99$ & $\$ 12.99$ & $\$ 14.99$ & $\$ 9.74$ & $\$ 10.85$ \\
\hline $\begin{array}{l}\text { Lisinopril }(20 \mathrm{mg}) \\
\# 30\end{array}$ & $\$ 4.00$ & $\$ 6.99$ & $\$ 13.59$ & $\$ 20.99$ & $\$ 11.39$ & $\$ 12.50$ \\
\hline
\end{tabular}

${ }^{1}$ All data were collected in December 2019 in Springfield, MA 01119.

*This price was calculated as the average between the three pharmacy types: mass merhandiser, supermarket and two national chains.

\section{DISCUSSION}

The GoodRx-discounted cash prices were significantly lower than undiscounted cash price across the different types of pharmacies. The analytical pharmacy average generic CV medication cash price was not significantly different from GoodRx-discounted cash prices at traditional pharmacies and was too significantly lower than undiscounted cash price at traditional pharmacies. It is of note that mass merchandiser pharmacy has its own national discount program for generic drugs with consumers often needing no additional coupons to receive the advertised discounted cash price. Average GoodRx-discounted cash price for generic CV medications at supermarket pharmacy was about half of that at the national chains. Luo et al. too identified that supermarket (grocery store-based) pharmacies offered lower generic drug prices compared with large chain pharmacies. ${ }^{7}$ In addition, Aurora et al. found that chain pharmacies had the highest cash price for the two agents they examined, azithromycin and levofloxacin. ${ }^{16}$ Accordingly, Mishra et al. showed that undiscounted cash prices for four commonly used erectile dysfunction medications were the highest at chain pharmacies. ${ }^{17}$ As for brandname CV medications, the GoodRx coupons appear to offer only marginally lower prices compared to undiscounted cash price.

Despite $90 \%$ of US drug volume being dispensed as generics, the quality of the generic drugs can vary. ${ }^{12,18,19}$ In 2019 alone, several generic drug recalls due to contamination and impurities attracted significant national attention. ${ }^{20-22}$ The analytical pharmacy claims to test each lot of dispensed medication for the concentration of active ingredient, inactive ingredients, and impurities and issues a certificate of analysis with each dispensed medication at no additional cost to the patient. ${ }^{23}$ Therefore, patients concerned about the quality of their generic drugs (particularly those taking medications with narrow therapeutic index, e.g., antiepileptics, warfarin, immunosuppressants) may consider analytical pharmacy instead of traditional pharmacies, as its undiscounted generic medication cash prices are similar to GoodRx-discounted prices at traditional pharmacies.

This study examined only one high-volume class of medications, and our results may not apply to other classes. We did not include independent pharmacies in our study as a list of prices from a nationally representative sample of individual businesses from across the country, not a single store price which was applicable to all geographically dispersed corporate pharmacies, had to be assembled. Independent pharmacies may offer patients the most affordable cash prices without any specific discount coupons. ${ }^{16,17}$ Aurora et al. showed that prices with GoodRx coupons were comparable with cash undiscounted prices at independent pharmacies, whereas, Luo et al. found independent pharmacies to have significant price variability and higher average prices on the GoodRx platform. ${ }^{7}$ Anecdotally, independent pharmacies may refuse to accept a GoodRx coupon because the company charges the pharmacies an exorbitant processing fee that often results dispensing prescription at a loss. For these pharmacies prices should be obtained directly from the pharmacies instead of via GoodRx as were done by Luo et al. In addition to payments from pharmacy benefit management companies (PBMs) and chain pharmacy contracts, GoodRx makes money by selling prescription data to third party companies. ${ }^{24}$ Health Insurance Portability and Accountability Act (HIPPA) rules do not apply to consumer-driven websites and apps like GoodRx. While many consumers already trade their privacy for the free use of a variety of online platforms and applications, some patients may be less willing to trade their prescription drug information for drug prices. ${ }^{25,} 26$

The generic drug gross margins calculated from GoodRxdiscounted prices were positive (Table 4), albeit expectedly lower than those that could be obtained from cash undiscounted prices. Wholesaler and manufacturer discounts off the invoice prices to pharmacies also contribute to gross margins but were not possible to account for in this study. ${ }^{27}$ In addition, considering the proprietary contractual arrangements between GoodRx and large chain pharmacies, it is difficult to determine the actual margins these traditional pharmacies earn once the GoodRx take back charges are processed. Future studies may consider comparing GoodRxdiscounted cash prices with cash undiscounted prices at independent pharmacies as current evidence is divergent on whether locally owned drugstores offer better prices than other pharmacies. 


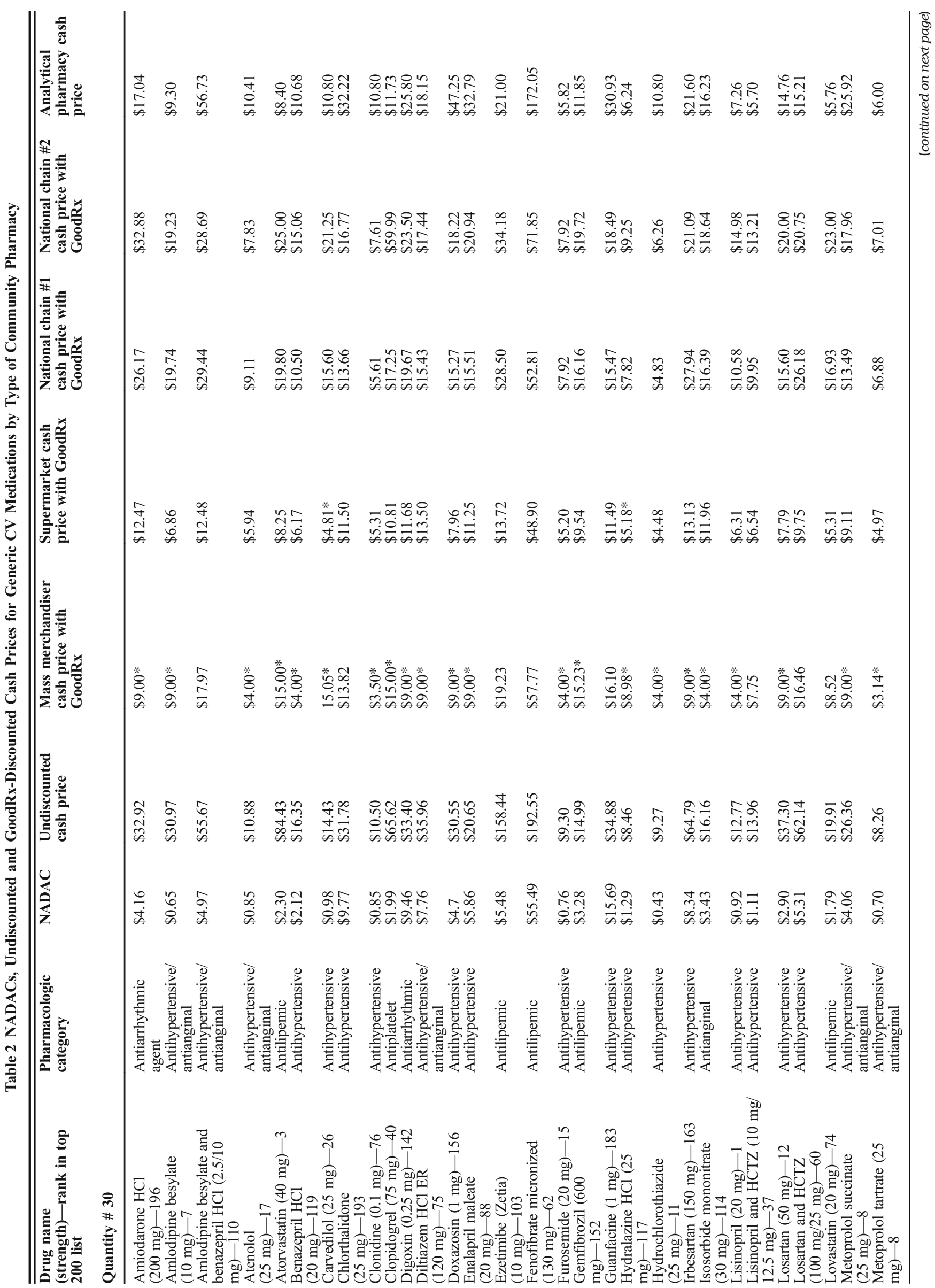




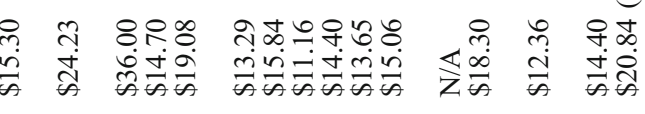

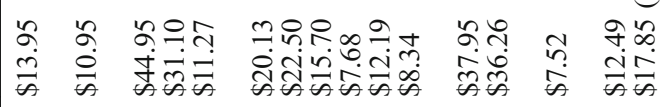

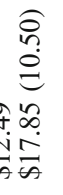

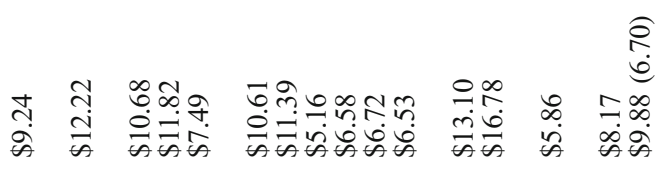

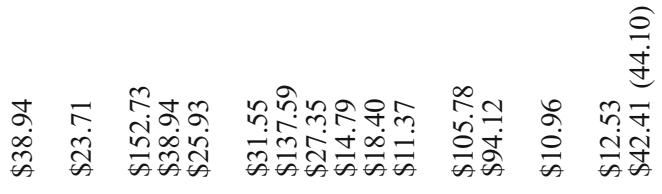

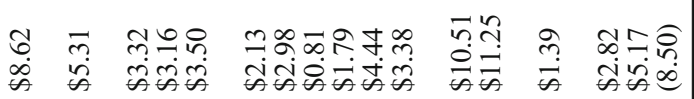

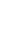
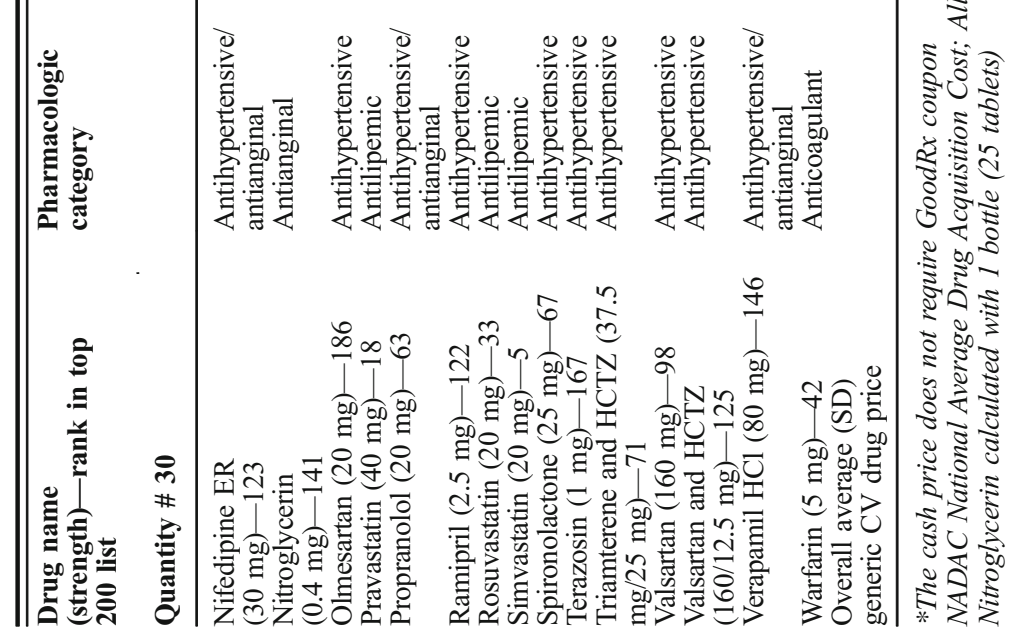


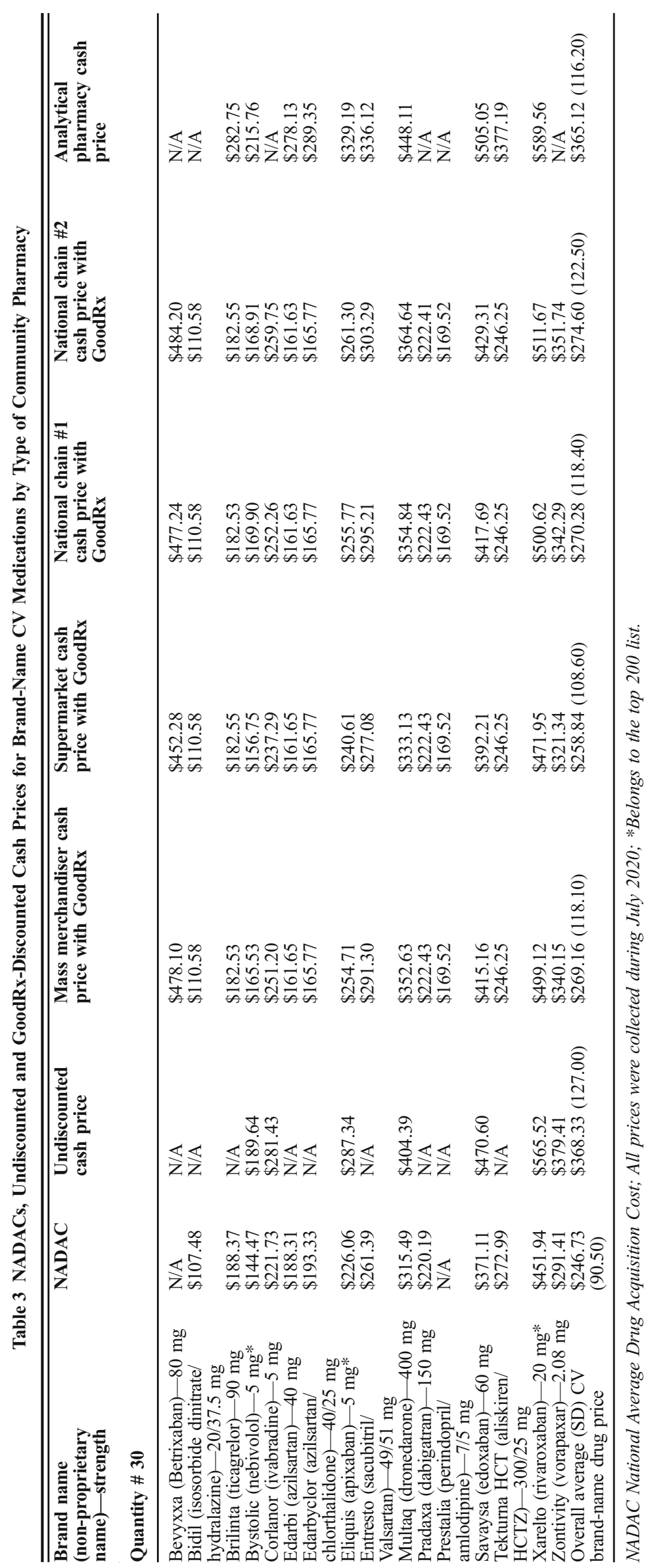


Table 4 Gross Margins from Sales of Generic and Brand CV Medications by Type of Pharmacy*

\begin{tabular}{|c|c|c|c|c|c|}
\hline & Mass merchandiser & Supermarket & National chain \#1 & National chain \#2 & Analytical \\
\hline Average gross (generic CV drugs) & $\$ 5.84$ & $\$ 4.71$ & $\$ 12.68$ & $\$ 16.56$ & $\$ 15.67$ \\
\hline Average gross margins (brand-name $\mathrm{CV}$ drugs) & $\$ 22.43$ & $\$ 12.10$ & $\$ 23.55$ & $\$ 27.86$ & $\$ 118.39$ \\
\hline
\end{tabular}

*Gross margins were calculated as differences between the average GoodRx-discounted price (cash price at the analytical pharmacy) and National Average Drug Acquisition Cost

Acknowledgments: The authors thank Tom Vamvanij for the editorial assistance with the manuscript.

Corresponding Author: Natalia Shcherbakova, $\mathrm{PhD}$; College of Pharmacy and Health Sciences, Western New England University, 1215 Wilbraham Rd., Springfield, MA 01119, USA (e-mail: natalia. shcherbakova@wne.edu).

\section{Compliance with Ethical Standards:}

Conflict of Interest: The authors declare that they do not have a conflict of interest.

\section{REFERENCES}

1. Martin CB, Hales CM, Gu Q, Ogden CL. Prescription Drug Use in the United States, 2015-2016. NCHS Data Brief. 2019:1-8

2. Hales CM, Servais J, Martin CB, Kohen D. Prescription Drug Use Among Adults Aged 40-79 in the United States and Canada. NCHS Data Brief. 2019:1-8

3. Lee S, Jiang L, Dowdy D, Hong YA, Ory MG. Attitudes, Beliefs, and Cost-Related Medication Nonadherence Among Adults Aged 65 or Older With Chronic Diseases. Prev Chronic Dis. 2018;15:E148. https://doi.org/ $10.5888 /$ pcd15.180190

4. Beer $\mathbf{L}$, Tie $\mathbf{Y}$, Weiser $\mathbf{J}$, Shouse RL. Nonadherence to Any Prescribed Medication Due to Costs Among Adults with HIV Infection - United States, 2016-2017. MMWR Morb Mortal Wkly Rep. 2019;68:1129-33. https://doi.org/10.15585/mmwr.mm6849al

5. Zhang JX, Lee JU, Meltzer DO. Risk factors for cost-related medication non-adherence among older patients with diabetes. World $J$ Diabetes. 2014;5:945-50. https://doi.org/10.4239/wjd.v5.i6.945

6. Lewey J, Gagne JJ, Franklin J, Lauffenburger JC, Brill G, Choudhry NK. Impact of High Deductible Health Plans on Cardiovascular Medication Adherence and Health Disparities. Circ Cardiovasc Qual Outcomes. 2018;11:e004632. https://doi.org/10.1161/CIRCOUTCOMES.118. 004632

7. Luo J, Kulldorff M, Sarpatwari A, Pawar A, Kesselheim AS. Variation in Prescription Drug Prices by Retail Pharmacy Type: A National Crosssectional Study. Ann Intern Med. 2019;171:605-11. https://doi.org/10. 7326/M18-1138

8. Pasalic D, Lingineni RK, Cloft HJ, Kallmes DF. Nationwide price variability for an elective, outpatient imaging procedure. J Am Coll Radiol. 2015;12:444-52. https://doi.org/10.1016/j.jacr.2014.11.024

9. Gato DM, Zenk S, Wilder J, Harrington R, Gaskin D, Alexander GC The availability of pharmacies in the United States: 2007-2015. PLoS One. 2017;12:e183172. https://doi.org/10.1371/journal.pone. 0183172

10. FDA Has Improved Its Foreign Drug Inspection Program, but Needs to Assess the Effectiveness and Staffing of Its Foreign Offices. United States Government Accountability Office; https://www.gao.gov/assets/690/ 681689.pdf; Accessed May 21, 2020.

11. Lever HM. A Physician's Perspective on Generic Drug Quality. $J$ Manag Care Spec Pharm. 2020;26:592-3. https://doi.org/10.18553/jmcp.2020. 26.5.592
12. Medicine Use and Spending in the U.S. A Review of 2018 and Outlook to 2023 The IQVIA Institute; https://www.iqvia.com/insights/the-iqviainstitute/reports/medicine-use-and-spending-in-the-us-a-review-of2018-and-outlook-to-2023; 2019; p. 48. Accessed May 24, 2020

13. Fuentes AV, Pineda MD, Venkata KCN. Comprehension of Top 200 Prescribed Drugs in the US as a Resource for Pharmacy Teaching, Training and Practice. Pharmacy (Basel). 2018;6. https://doi.org/10. 3390/pharmacy6020043

14. Valisure Sign Up. https://shop.valisure.com/signup; Accessed May 21, 2020.

15. National Average Drug Aquisition Cost. https://data.medicaid.gov/DrugPricing-and-Payment/NADAC-National-Average-Drug-Acquisition-Cost-/ a4y5-998d; Accessed May 24, 2020.

16. Arora S, Sood N, Terp S, Joyce G. The price may not be right: the value of comparison shopping for prescription drugs. Am J Manag Care. 2017;23:410-5.

17. Mishra K, Bukavina L, Mahran A, et al. Variability in Prices for Erectile Dysfunction Medications-Are All Pharmacies the Same? J Sex Med. 2018;15:1785-91. https://doi.org/10.1016/j.jsxm.2018.10.011

18. White CM. Generic Drugs Not as Safe as FDA Wants You to Believe. Ann Pharmacother. 2020;54:283-6. https://doi.org/10.1177/ 1060028019881692

19. Gibson R, Singh J. China Rx: Exposing the Risks of America's Dependence on China for Medicine. Guilford, CT: Prometheus Books; 2018.

20. White CM. Understanding and Preventing (N-Nitrosodimethylamine) NDMA Contamination of Medications. Ann Pharmacother. 2020;54:6114. https://doi.org/10.1177/1060028019892222

21. FDA Updates and Press Announcements on Angiotensin II Receptor Blocker (ARB) Recalls (Valsartan, Losartan, and Irbesartan). https:// www.fda.gov/drugs/drug-safety-and-availability/fda-updates-andpress-announcements-angiotensin-ii-receptor-blocker-arb-recalls-valsartan-losartan; 2019 Accessed May 24, 2020

22. Valisure Division of Dockets Management, Food and Drug Administration. Valisure citizen petition on ranitidine.; https://www.valisure.com/ wp-content/uploads/Valisure-Ranitidine-FDA-Citizen-Petition-v4.12. pdf; Accessed May 24, 2020.

23. Valisure Certificate of Analysis. https://www.valisure.com/analysis/; Accessed May 24, 2020.

24. GoodRx Saves Money on Meds-It Also Shares Data With Google, Facebook, and Others. https://www.consumerreports.org/health-privacy/ goodrx-shares-users-health-data-with-google-facebook-others /; Accessed May 19, 2020.

25. Esteve A. The business of personal data: Google, Facebook, and privacy issues in the EU and the USA. Int Data Privacy Law. 2017;7:36-47.

26. Grundy $\mathbf{3}$, Chiu K, Bero L. Commercialization of User Data by Developers of Medicines-Related Apps: a Content Analysis. J Gen Intern Med. 2019;34:2833-41. https://doi.org/10.1007/s11606-019-05214-0

27. Aitken M. Understanding the Pharmaceutical Value Chain. Pharm Policy Law 2016; 18:55-66. https://doi.org/10.3233/PPL-160432

Publisher's Note Springer Nature remains neutral with regard to jurisdictional claims in published maps and institutional affiliations. 